\title{
A Development Approach on Lean Advertising and Implementation in An Automotive Product Distribution Industry
}

\author{
Tamilvanan.N \\ Department of mechanical engineering, \\ PSG College of Technology, \\ Coimbatore, Tamilnadu, India.
}

\author{
Syath Abuthakeer.S \\ Department of mechanical engineering, \\ PSG College of Technology, \\ Coimbatore, Tamilnadu, India.
}

\begin{abstract}
Lean manufacturing is a methodology that focuses on the reduction of wastes. The tools and techniques under the lean manufacturing were implemented according to the industry and the problems faced. Normally different methodologies were used while implementation of lean. In this paper a new conceptual methodology is developed in order to study the impact on lean implementation on automotive distribution industry. It also discussed different types of barriers while implementing the new methodology on a particular automotive distribution industry.
\end{abstract}

Keywords-Lean advertising; lean on distribution industries; campaigning; branding and signages.

\section{INTRODUCTION}

Lean manufacturing is also a managerial philosophy. So, in this paper it reveals how new lean methodology were developed by the integration of some managerial methodologies/tools \& techniques. It also explained how the developed methodology has been pilot implemented in an automotive products distribution industry. It also discussed about the barriers while implementing the new lean implementation methodology in the particular industry. According to the efficiency of the developed methodology implementation in an automotive product distribution industry it will convert into a generalized methodology for the further implementation to other automotive products distribution industries.

\section{METHODOLOGY OF THE STUDY}

Normally a methodology will be based on the current scenario of the industry. In this methodology as a first step a questionnaire should be created in order to know the awareness and knowledge about the lean manufacturing and its concepts in the industry. Then as a second step a particular industry must be selected for the pilot implementation. Here, an automotive product distribution industry has been selected for the pilot implementation. Then the selected industry must be approached by the team of lean experts in order to explain the benefits of lean implementation. Then the developed questionnaire must be given to the selected industry and answers must be recorded. According to the answered questionnaire we can able to segregate the problems and appropriate lean tools and techniques must be selected for the implementation. Then an awareness programme should be conducted for the lean manufacturing and its concepts on distribution industries and also explain the current lean implementation and its training to the employees. Then after some periods a questionnaire should be developed and given to the industry after the lean implementation in order to know the efficiency and the impact on lean implementation. It also discussed some of the challenges faced while implementation [1].

\section{LEAN ON DISTRIBUTION INDUSTRIES}

Many implementations based on lean concepts was executed successfully worldwide. Today modern industry world lean concepts and techniques also developed equally with the technology. Some industries were wrongly understood that only a technological improvement can improve the industry efficiency. It is based on the industry needs. So, implementing methodology may be a traditional and technological. So we need a generalized methodology for distribution industries based on problems. In that an automotive lubricant distribution industry is taken for the new lean concepts implementation. The major problems faced on this particular industry are non popularity/unawareness among the peoples. Although this company has / had a quality product. So lean advertising is a technique used in this automotive distribution industry. For a change different methodology integrated into / with lean advertising and pilot implemented in this industry [2]. This paper reveals what are all the techniques followed while implementation, challenges and barriers while implementation.

\section{CAMPAIGNING}

As a first step of our implementation process campaigning process should be done by our marketing executives at each distributors shop outlets in a selected location which will be coming under the selected pilot implementation automotive distribution industry's distribution geographic location. The executive will be interacting with the customers for a week. Not only interacting and promoting the products, Each of our campaign location executives will be providing a form in order to note the customer's details. The form contains name of the customer, bike used, Product brought, contact number, email Id, location. By this data after a period we can get the feedback forms / formed the customers about our product and their rating and experience in an email. By that we can get the 
impact on campaigning process. This will be used for final impact values. As a first step of our implementation process campaigning process should be done by our marketing executives at each distributors shop outlets in a selected location which will be coming under the selected pilot implementation automotive distribution industry's distribution geographic location.

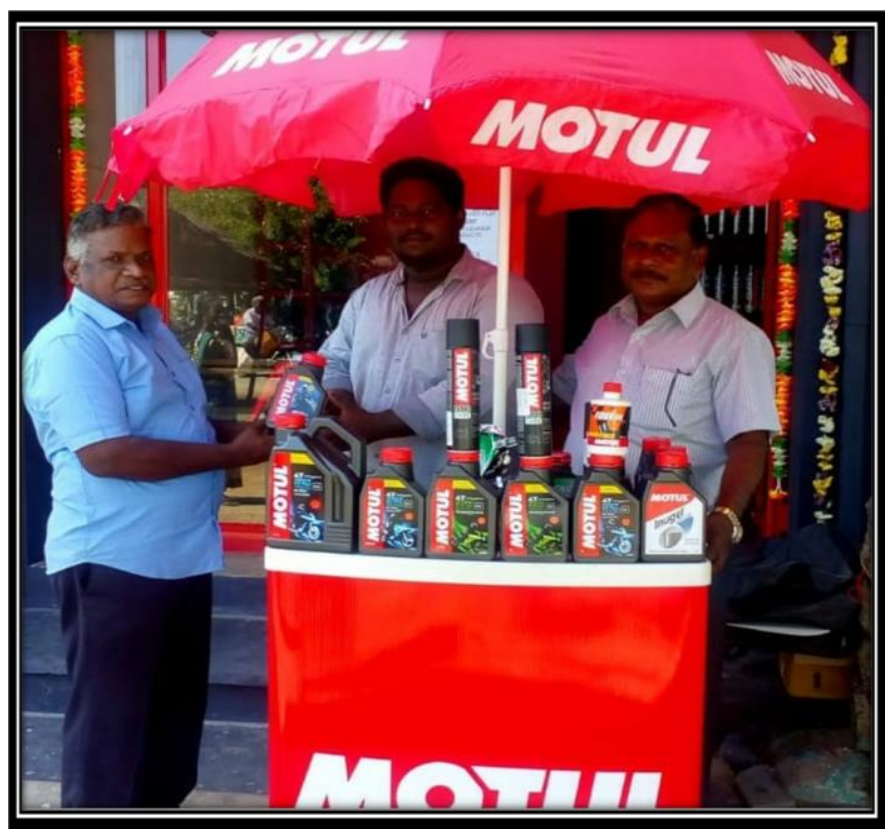

Fig. 1. Campaigning process

\section{V.BRANDING AND SIGNAGES}

After the campaigning process the next step is to select the hotspot locations like famous automotive products distributors and mechanic shops under the particular pilot implementation distributor's geographic location. Then branding work like promotional events should be implemented into all retailers' outlets, mechanic shops like creating a name board for the shops highlighting our products. Because, the main reason for this pilot implementation are to make awareness about the product of the particular geographical location. So, branding and signages would be the second stage of the implementation process under lean advertising [4].

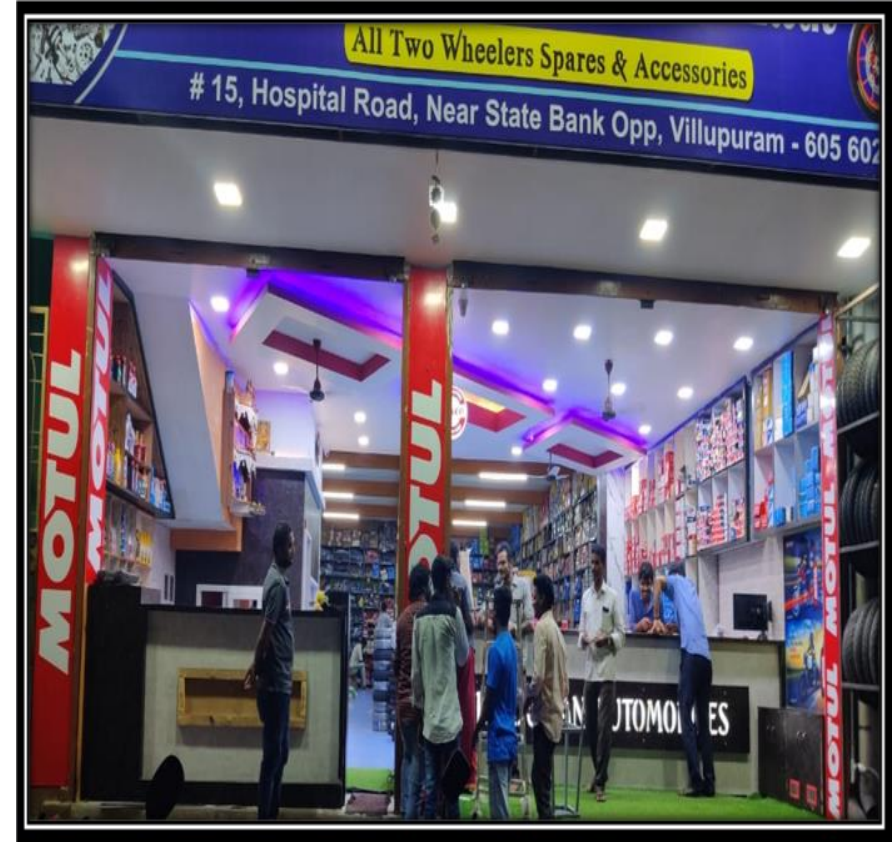

Fig. 2. Branding and signages

\section{CHALLENGES FACED WHILE IMPLEMENTATION}

Normally while implementation of any new methodology into an organization/industry will have some challenges. Some may be solved successfully and some may be unsolved. It is based on the industry where we are approaching and it also depends on the employees from top level to low level in that particular organization. Same like that when we are ready for our lean implementation in a private automotive products distribution industry we faced some major challenges. The first thing is although we have the very good team and the methodology in our hands we have to get the approval for the company for our lean implementation in that particular industry. So as a first step we have explained about our lean methodology to that particular industry and make an awareness program about the lean concepts and its benefits of distribution industries [5]. This was a first major challenge while implementation. A methodology has / had been followed in that particular industry for many years. When we are integrating our new methodology means employees will feel bad and they won't show any interest in our methodologies. So we have to explain the major benefits of our lean concepts in their industry without affecting the employees in any manner. Then second challenge is about training the employees towards our implementation methodology and towards lean concepts. While training the employees we cannot regret some of the employees due to some lag in understanding. We should train them equally and they should be allotted to the work according to their level and interest. So by our training we should make the employees as well trained employees in their allotted field after the implementation. Then as a third challenge while implementation the lean advertising concepts we are in the position to choose the right place and some hotspots for our methodology like campaigning and branding and signages. These are all the major challenges we have faced while 
implementation of our lean concepts in that particular industry [6].

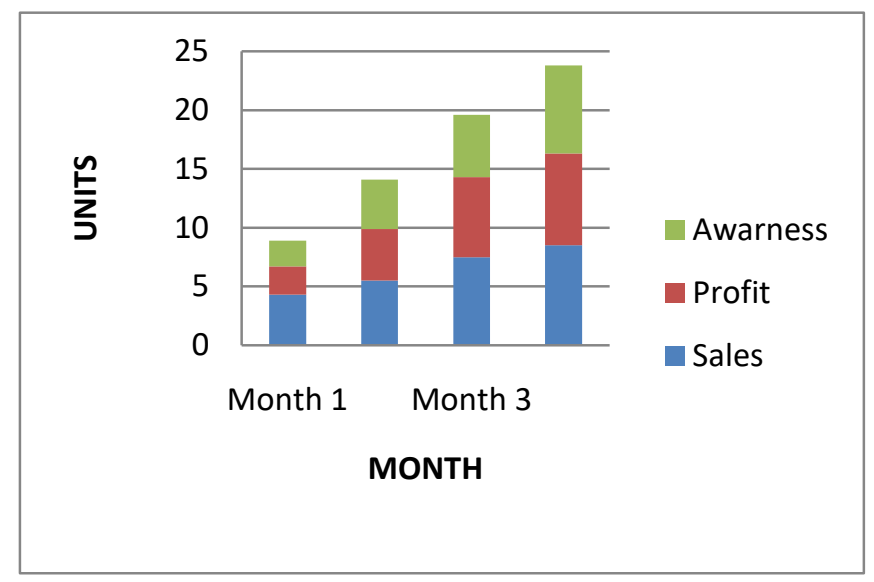

Fig. 3. Column type chart representation

\section{CONCLUSION}

After the successful implementation of the improved lean methodologies into an automotive distribution industry. The awareness among the people increases as compared to the previous one (Before implementation). It also improved the sales of the automotive distribution industry after the improved lean advertising has been integrated into the particular industry. In this paper it the lean advertising technique was pilot implementation successfully. By keeping this as a reference the further improvements may be done and implemented into many distribution industries in future.

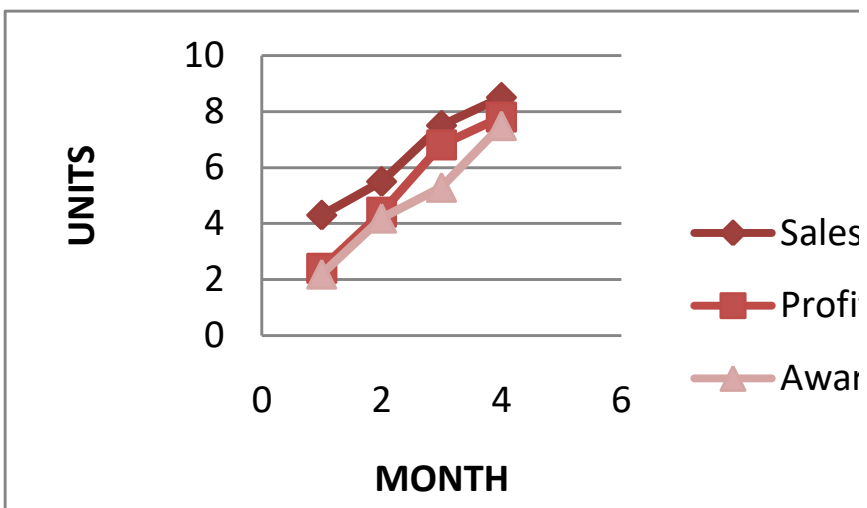

Fig. 4. Line type chart representation

\section{REFERENCES}

[1] D. Arfmann and F.G. Topolansky Barbe, The Value of Lean in the Service Sector: A Critique of Theory \& Practice, Center for Promoting Ideas, USA, 2014.

[2] D.H. Taylor, An application of value stream management to the improvement of a global supply chain: a case study in the footwear industry, International Journal of Logistics: Research and Applications, Vol 12, No 1, February 2009.

[3] F. Damrath, Increasing competitiveness of service companies: Developing conceptual models for implementing Lean Management service companies, Thesis ID number 2012:125, Politecnico di Milano. Como, 2009.

[4] Ministry of Economy and Trade (2014). Lebanon SME strategy: A roadmap to 2020. Ministry of Economy and Trade Available at http://www. economy.gov.lb/public/uploads/files/6833_5879_4642.pdf.

[5] J. Bicheno and M. Holweg, The Lean Toolbox: The Essential Guide to Lean Transformation, Buckingham: PICSIE Books, 2009.

[6] A. Bonacorsi ... [et al], Service value stream management (SVSM): Developing Lean Thinking in the Service Industry, Journal of Service Science and Management 20 